\title{
Who Wants the Second Child: A Test Based on Leibenstein's Cost-Utility Theory
}

\author{
Jialin $\operatorname{Yan}^{1, \mathrm{a}}$ \\ Primary education college, Capital normal university, Beijing, 100089, China \\ Corresponding author's e-mail: angela@cas-harbour.org
}

\begin{abstract}
To counter China's continued falling fertility rate in recent years, the government has introduced a two-child policy, but the expected effect is not obvious. Given that the 90s generation is now in its prime childbearing ages, the government should consider the willingness of this 90s generation to have a second child. Based on Leibenstein's cost-utility theory and an online questionnaire, this essay analyzes the main determinants of the 90s willingness of the second child. The findings highlight the importance of individual upbringing environment (family, school and society), personal income and social pressure (employment, housing and children's education), which accounted for $68.89 \%$ respectively of variation in demand for the second child.

Keywords: 90 s generation, the second child, Leibenstein's cost-utility theory
\end{abstract}

\section{INTRODUCTION}

At the end of 2019, the total population of mainland China broke through 1.4 billion. Meanwhile, the annual fertility rate decreased to $10.48 \%$, the lowest figure since 1952 according to the sixth national census. Although the government keeps rolling out the two-child policy in mainland China, the fertility rate remains low. It is crucial for the government to consider the attitudes of the $90 \mathrm{~s}$ generation to have a second child while implementing the Two-child policy. This essay combines the statistics of the sixth national census and a questionnaire to investigate the drivers of the willingness of the 90s generation of only child and non-only child who live in Beijing to have a second child, and analyze the factors based on Leinstein's cost-utility theory. A questionnaire is used in this study to investigate these factors, drawing from Leibenstein's cost-utility theory. The respondents in this study are those who live in Beijing, being the only child or non-only child.

\section{LEIBENSTEIN 'S COST-UTILITY THEORY}

Harvey Leibenstein put forward the cost-benefit theory of children in 1954. The theory analyzes the costs and benefits of raising children, distinguishing between direct and intermediate costs. Children's utility is roughly separated into 5 parts: income utility, consumption utility, insurance effect utility, anti-risk utility and household utility. Families determine whether to have the nth-child via analyzing the cost and utility of the nth-child.

\section{THEORIES AND DATA}

A total of 300 questionnaires were issued. Among them, 294 were recovered, and 268 were found to be valid. In the survey, 16 districts in Beijing were randomly selected through online questionnaires, with "90s generation" as the research objects.

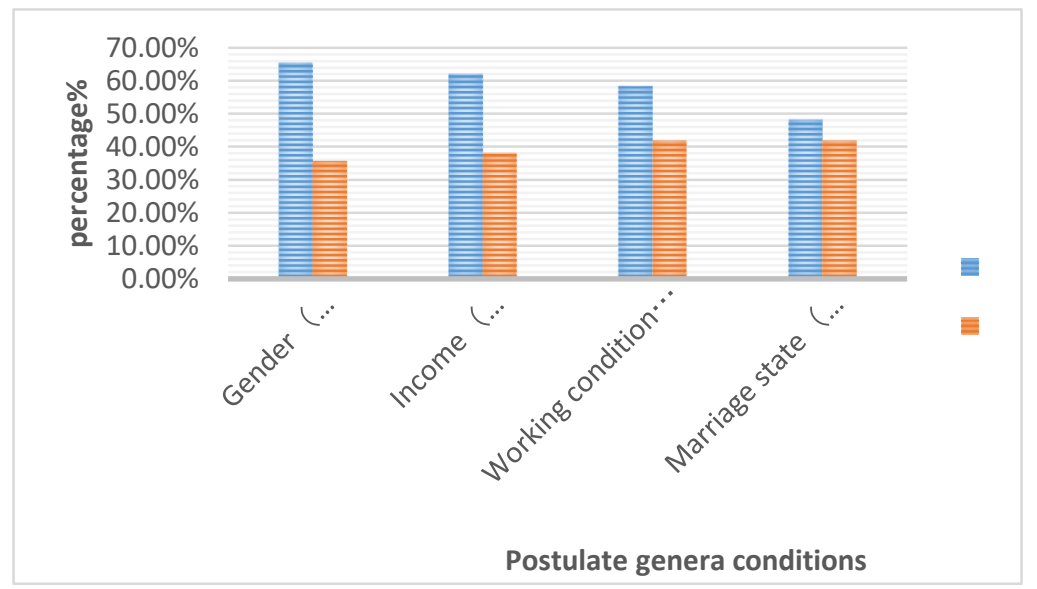

Figure 1 Distribution of the basic situation of 90s generation of only children and non-only children. 


\section{RESULT AND ANALYSIS}

\subsection{The general willingness of a second child of the people born in the 90 s}

According to the survey, $46 \%$ of the 90 s generation are willing to have a second child. The $90 \mathrm{~s}$ generation's attitude towards the second child matter for fertility. However, other factors such as partner's and parent's opinions play a crucial role in whether to have the second child as well.

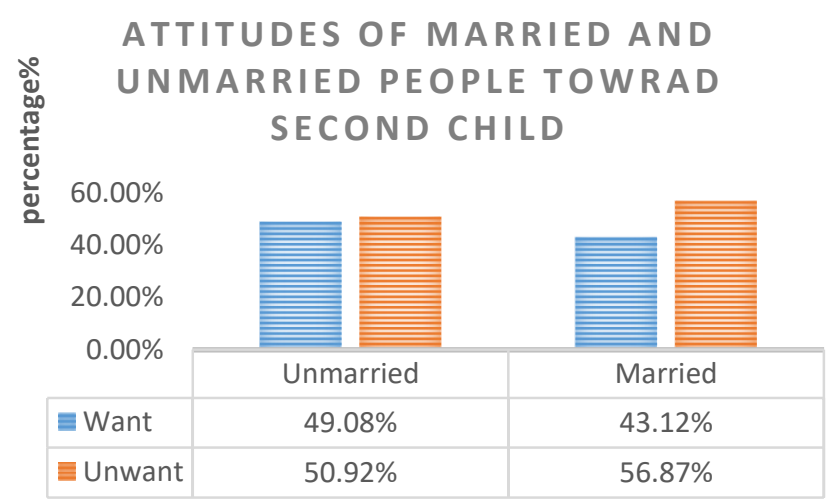

Figure 2 Attitudes of married and unmarried people toward the second child.

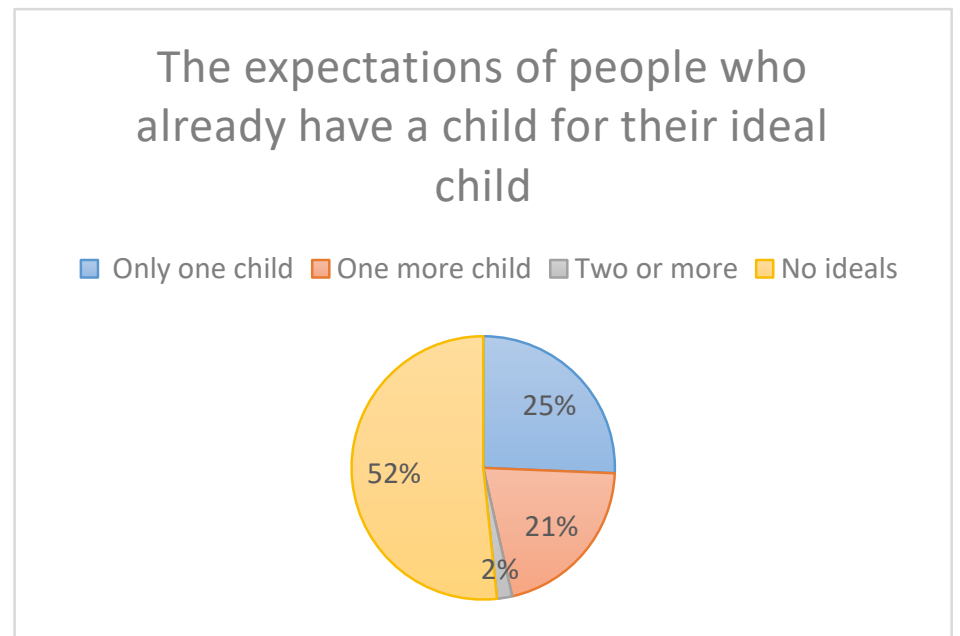

Figure 3 The expectations of people who already have a child for their ideal child.

The questionnaire results show that, among the 90s generation, the whole group is reluctant to have a second child. Most of those who were born in the 1990s and already have a child have not decided whether to have a second child or more, the number of whom accounts for $52 \%$; the number of those born in the 1990 s who do not want to have a second child, namely, $25 \%$, is similar to that of those who only want one, namely, $21 \%$. 


\subsection{Main determinants of desire for a second child}

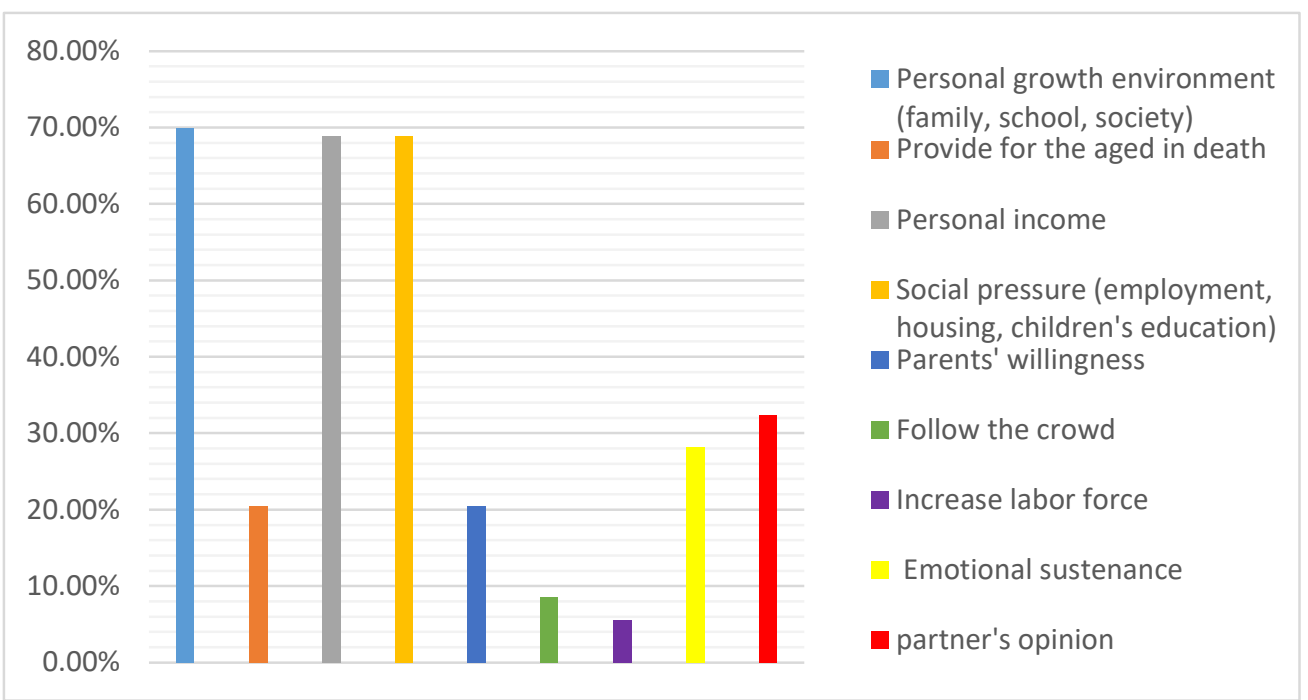

Figure 4 Main factors impacting the willingness of the second child.

According to the survey results, the three most important factors impacting the 90s generation to have a second child are individual growth environment (family, school and society), personal income and social pressure (employment, housing and children's education), reaching $68.89 \%$. What is more, the partner's opinion is $32.34 \%$, emotional sustenance accounts for $28.25 \%$, and parents'

\section{THREE MAIN FACTORS BASED ON LEIBENSTEIN'S COST-UTILITY THEORY} willingness and elderly cares are similar, stand for $20.45 \%$.

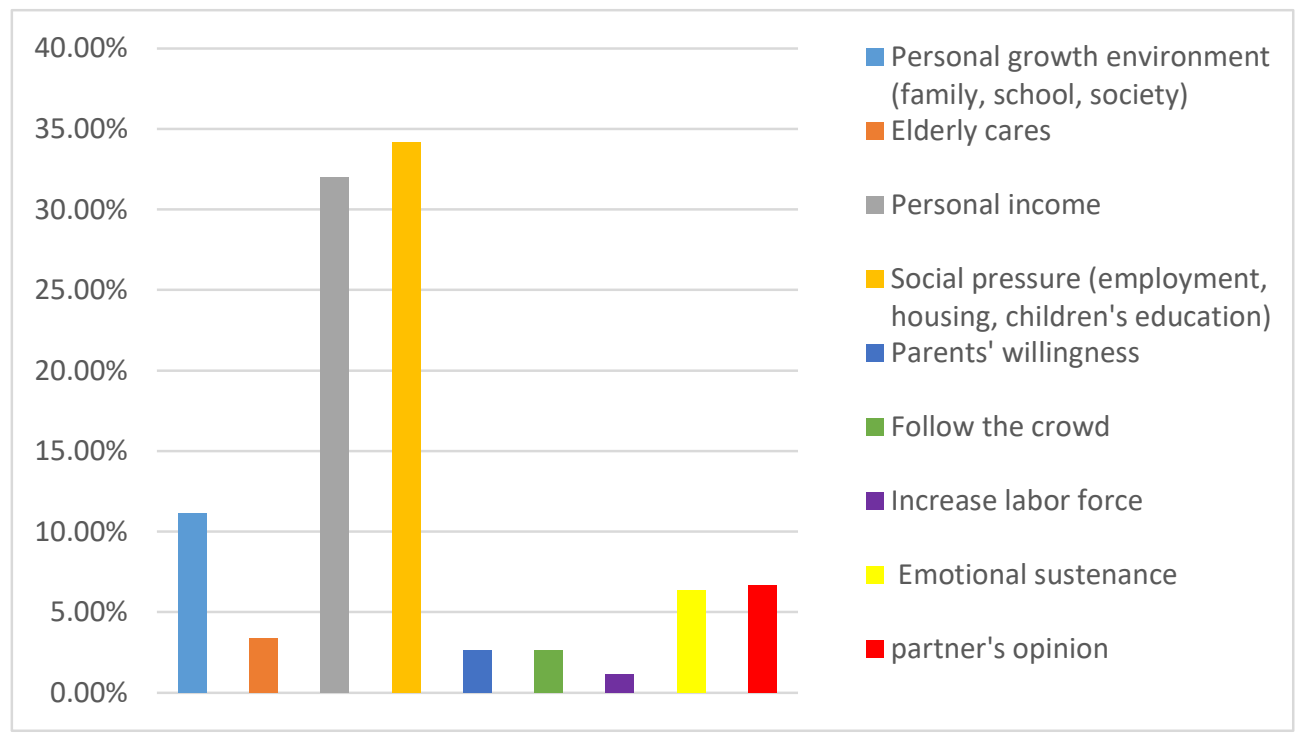

Figure 5 Prior factors affecting desire for a second child.

Three main factors stand out as driving the $90 \mathrm{~s}$ generation's attitudes about the second child. These include personal growth environment (family, school and society), personal income, and social pressure (employment, housing and children's education). These three factors account for $11.15 \%, 31.97 \%$, and $34.2 \%$ respectively of the variation in attitudes to having a second child. 


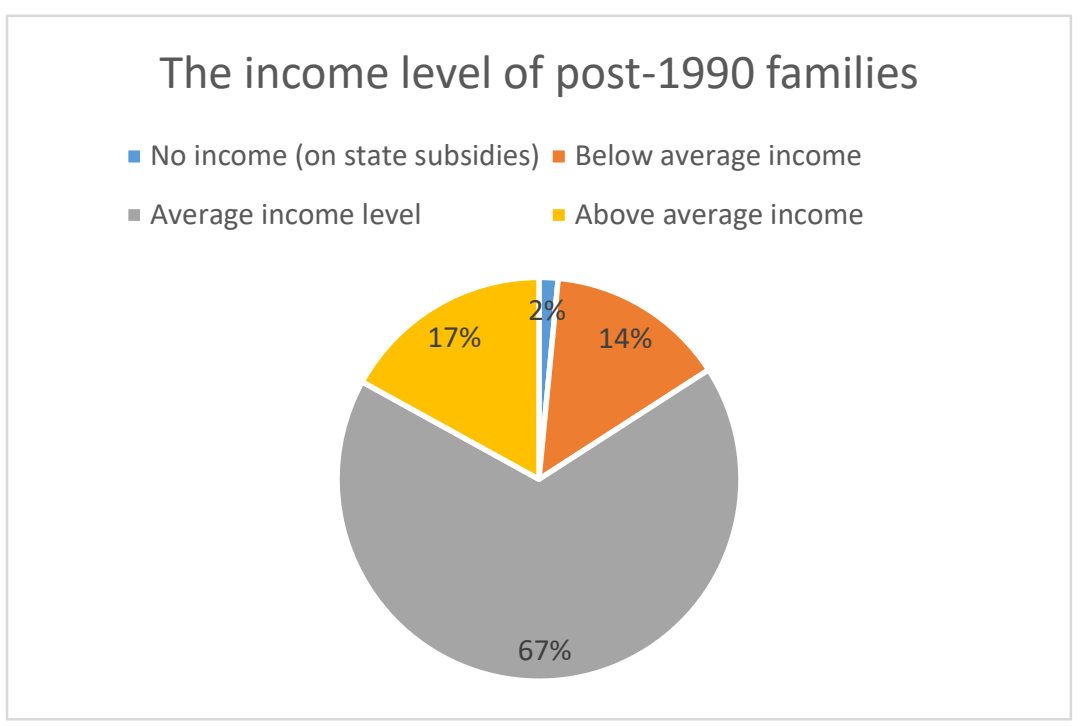

Figure 6 The income level of post-1990 families.

Several telephone interviews were taken as well after an online questionnaire. Dana, a young single college student expressed that having a second child was unpractical to her, when taking the high-prices of commodities and house into consideration. From her perspective, having a second child means paying double or even more fees for their household as well as extra education in the future.

According to the latest analysis by the National bureau of statistics in 2018, the average house selling price in Beijing is 37,420 yuan $(4263 \$$ roughly) per square meter. However, in Beijing, the minimum wage is 2,200 yuan (309\$ roughly). If it is supposed to buy a 100-square-metre department at the minimum wage, people would have to work for at least 200 years.

According to the survey, most respondents report to have an average income, and the second most represented income level is above average. With increased affluence, parents have begun to pay attention to the growing environment of their children, such as family environment, school environment and social environment.

The environment under which children are brought up is significant for the development of a child. Prospective parents consider the children growing environment before having decide to have a child. Most parents spare no efforts to ensure their children to have the best childhood possible. They do this by limiting exposure to early traumatic experiences in order to not cast a shadow to their future. Furthermore, many parents opt to advance their own education to improve their socioeconomic position and set a good example for their children.

Because of the shortage of educational resources and the unbalanced distribution, most parents continuously increase the educational expenses of children to improve their school environment. According to the White paper on family education consumption in 2017, education expenditure accounted for more than $20 \%$ of a family's annual income in 2017, with remedial classes playing a major role. The rising cost of education has increased the marginal cost of having a second child[1]. Moreover, there is a popular saying in Chinese "Do not let the children lose at the starting line". According to the 2019 white paper on Chinese family gestation methods, fetal education has become more earlier than before as fetal education cycle lengthening.

The second trimester is the peak period for fetal education, which is dominated by music and storytelling during pregnancy. According to the 2019 white paper on Chinese family gestation methods, more than $30 \%$ of users in lower-tier cities spend more on paid fetal education, such as buying fetal education equipment/courses. $88 \%$ of pregnant mothers list early education as a necessary item after the birth of their children. Moreover, the beginning of early education is getting earlier, showing a trend of "early education". In the course of early education, pregnant mothers are more inclined to improve their children's ability on different fields, so they bring their children to certain of thinking and logic classes, swimming classes and concentration training, which account for $50 \%$. Some middle-class families also invest in in order to cross classes. Hence, parents should consider multiple of things before having a child.

Personal income plays a crucial role on whether to have a second child, because parents not only have to pay children's normal education fee, extra education fee such as tutorial classes, but also household fee. Since the implementation of Beijing's 317 new policy was put into the estate market to control house prices, it has curbed the excessively rapid rise of housing prices. However, housing prices are still at a high level[1]. Having a second child means families should face the problem of buying or renting larger houses. In order to promote the children's education, some families attempt to buy apartments in a better school district. As a result, the increasing mortgage brings a high pressure on a family. Even if they rent a house, it still implies a much higher cost for parents looking for better education districts.

High house prices and rents pushed up the marginal cost of having a second child. In addition, according to the 2019 
white paper on Chinese family gestation methods, the proportion of young Chinese parents staying at home full-time is rising, accounting for 58.6 percent, which means that whether they have extra income or they could not support their family. From Leibenstein's cost-utility perspective, the cost of having children include both direct and indirect costs. Direct costs refer to the expenses of having a child, the cost of later cares as well as the cost of raising and educating children. Nowadays with the development of economy, the expenditure of having a child or raising a child has obviously increased. Sometimes the income could not support many children, which makes low-income families self-select to have only one child. "could not afford to be born or raised" became the biggest reason for 90s generation to not have a second child, and income is the specific manifestation of whether they can afford them[2]. As a result, parents should consider whether they could support their children for a better life before having a child especially the second child.

Societal pressure also triggers a phenomenon that multiple of 90s generation select not to have a second child. Due to the generally high education level of the parents, raising a child requires not only providing them with enough food and clothes, but also offering them high quality of education. The parents having two children sometimes need to spend more time and energy on accompanying their children than those parents having less kids. In the 2019 white paper on Chinese family gestation methods, in high-line cities, such as Beijing and Shanghai, working mothers account for $46.8 \%$ of the number of mothers. From giving birth and before they return to work, working mothers' worry about their hiatus from work and the challenge of catching up. They worry that they won't be able to keep up with the pace of the workplace. In this regard, physical recovery is the first step to return to the workplace, followed by supplementary training for job skills. Consequently, some parents had to quit their job. Such a shift fuels negative emotions, such as anxiety, depression, which could be vented to their children, ultimately forming a vicious cycle of parental anxiety and poor nurturing [3]

\section{ANALYSIS ON THE MINOR FACTORS AND RELEVANT REASONS}

Besides, more secondary factors affect the desire to have a second child, such as partner's opinion (2.34\%), emotional sustenance $(28.25 \%)$, parents' willingness to provide for the elderly parents $(20.35 \%)$.

Initially, some in the 90s generation sought a second child for the second child could help them with elderly cares in the future. With the impact of market economy and modern media on society, the new value infiltrates all-roundly to the traditional conception, so that the old-age security, female pension concept has been changed greatly. The two-child policy provides people with a suitable choice for women pension [4]. According to the cost-utility theory of American demographer Harvey
Lebenstein, the idea of providing for the aged, which plays an important role in the marginal utility of children, will promote the family's willingness to have more children. For elders, the increasing number of children is associated with emotional and material benefits (parent-child interaction, life care and economic support). Therefore, families hold more children hoping for better care during their old age, and a comfortable life during retirement[4] Plenty of 90s generation having only one child realize that when they grow older, they may become lonely, because their children are busy at their work or family and have no time to accompany them. More children means sometimes more company. Hence, the second child could be an emotional sustenance to some extent.

As to the partner's opinion, in most regions in China, women are required to have boys to carry on the family line. If the first child is a girl, women would be crowed out by family, and even may face forced abortions. Nevertheless, after the young generation obtained higher education, and after multiple revolts about the women's rights, people came to realize the equality of the female and male rights. Couples began to pay more attention to the needs of each other. Therefore, the family began to concern the requirement of women. And in a family, partner's opinion is very important for the second child as well[5].

Last but not least, due to the heavy workload and trivial things in life, a majority of children receive daily care from grandparents. However, as those elder people grow older, they have less energy to take care of more children. Furthermore, some people are quite willing to obey their parents. As a result, the 90s generation would take their parent's opinion into consideration, when they decide to have a second child.

\section{CONCLUSION}

This essay mainly investigated the factors, which trigger the 90s generation's attitudes toward the second child. In the mainland China, the adjustment of the family fertility policy by the society and the government is based on the population size and structure, the level of social and economic development, the alleviation of population pressure, among other factors. Although the government has released the two-child policy, it still has not created the corresponding conditions for the 90 s generation to have children. At the same time, in order to encourage young people to have the second child, certain policies could be put in place to subsidize the cost of raising children. Eliminating gender discrimination in workplace is significant as well, and it increases the job opportunities for female. However, there are also some limitations in this study, the questionnaire only investigate the willingness of 90 s generation in Beijing. Other provinces must be covered. Given the diversity of places such as cultures, education and economy, the main factors could be different as well. More data should be collected among different provinces in mainland china. Furthermore, certain of research should be done among the young 00s 
generation, since the $00 \mathrm{~s}$ generation are going to be parents, however their attitudes are different, given that this new generation is different and is now entering its reproductive ages.

\section{ACKNOWLEDGMENT}

First and foremost, I would like to show my deepest gratitude to my teachers and professors in my university, who have provided me with valuable guidance in every stage of the writing of this thesis. Further, I would like to thank all my friends and roommates for their encouragement and support. Without all their enlightening instruction and impressive kindness, I could not have completed my thesis.

\section{REFERENCES}

[1] S. Huang. Analysis of factors influencing the effect of fertility policy implementation and Suggestions on measures--based on Leibenstein's cost-utility theory. Human resources management, 2018(12).

[2] Q. Zhu. Empirical analysis of fertility intention under the universal two-child policy-- take longquanyi district of chengdu city as an example. Modern business, 2018 (36).

[3] H. Cheng. A brief discussion on the source of parental pressure in a two-child family. Modern Communication, 2019(20).

[4] H. Lu, F. Qi, Y. Zheng. A study on the influencing factors of women willingness to have a second child -from the perspective of the nature of employment and the concept of providing for the aged. South China Population, 2017(3).

[5] S. Zhang. The conflict and resolution of the change of fertility policy on women's rights. Legality Vision, 2018(13) 